\title{
DIGITAL NATIVES AND MOBILE TECHNOLOGY ADDICTION
}

\author{
S.C.Spangler, Robert Morris University, scsst295@mail.rmu.edu \\ Robert Joseph Skovira,Ph.D., skovira@rmu.edu
}

\begin{abstract}
Information technology and mobile technology has become so prevalent in our society and culture today that it is consider nerd chic to have the newest and greatest innovations at all times. Digital natives, youth that have grown up in a world where telephone cords never existed and the Internet is as important as the air we breathe, can not disconnect from the tools or the Internet. Upon connectivity disconnection, the culture's youth instantaneously face anxiety issues and physical symptoms similar to drug addiction detoxification. This paper seeks understand mobile technology addiction and pin point its knowledge and acceptance in the digital native culture.
\end{abstract}

Keywords: Digital Natives, Mobile Technology, Technology, Addiction, Innovations, Culture

\section{INTRODUCTION}

Two digital natives tragically went to heaven early in life. Upon getting to the pearly gates, one youth asked the other, "Do you think we will meet God soon?" The second one texted back, "Hold on, I'll ask Siri to Google the wait time!" In today's digitally sophisticated society, the digital youth are presumed to be abundantly proficient with technology, speed orientated and infatuated with everything technological. These statements or labels have stereotyped the youth culture (or teenage and post high school students) since the early 90's with Tapscott's [14] Millennial rising theories and the paradigm shifting thoughts of Prensky's [7] coining "digital natives." Ethnographers all accept two have circumnavigated a deep and concentrated observation of the culture to understand if these traits are still affirmatively sticking to the matrix. This paper seeks to examine one aspect or trait in the culture and understand through rich covert ethnographic observations, and a series of in-member checking of the data focus groups, if Internet and technology addiction is truly a reality or a myth in the digital native paradigm.

\section{PROBLEM STATEMENT AND PURPOSE}

This research will fill in the current gap in the digital native literature on addiction in the culture. This paper will first seek to understand through current literature the meaning of technology addiction in the digital native culture. Second, the research will examine the extent of the digital native's addictive behaviors. And finally, this paper will propose the point of the Digital Natives' addiction's conception.

\section{LITERATURE REVIEW}

MIT's myth busting professor Sherry Turkle [14] anointed the current digital native culture as one living "alone together." The research disclosed a world where digital natives, youth considered to have grown up in a world filled with technology and having technology sophistication, are living right next to one another and socially disengaged because of technology. This theory was first expressed in her coincidental first novel that stated youth were living a life "on a screen" as the computer generation of kids and their parents had embraced the home personal computers. A market filled with low-cost personal computers and Internet accessibility was crushing the technology gap.

Carr [5] expounded on this digital technology explosion formulating a paradigm shifting theory about negativity in the culture. The paradox suggested personal computers, and the Internet were combined a force that was changing socialization and creating animatronics cultures suffering from brain plasticity issues. Prensky [7] and Tapscott [13] suggestively pointed towards the digital native culture as having brain functioning issues because of their multitasking behaviors. Their insights were more realistic and positive than exploitive, but suggested the youth might suffer damaging or complex deconstructions in their mental or cognitive functions because of the speed and constant shifting mental behaviors in the matrix. 
Bauerlein [1] first constructed a deeply negative paradigm shift about the culture that illuminated its negative habits and behaviors. Bauerlein's digital natives were labeled as unsophisticated youth surfing the Internet as a methodology to procrastinate, and become bewildered in the matrix. Bauerlein strongly suggested the days of social awareness, opportunity generating, and engagement were long gone and bypassing Howe \& Strauss' [6] digital native assessment. Nevertheless, the culture was transforming and changing through technology usage and time investment on the Internet.

Boyd's [2] ethnographic investigation into the teenage digital natives suggested a culture of socially disengaged youth that lived on Social media sites to become informed and enlightened. The now (2014) digital natives were conducting life even deeper in the Internet matrix and expressing their lives on social media sites similar to Turkle's [14] original paradigm. Boyd's research, which expounded on how cyberbullying or "pranking" is a utilized on the net, is alive today. The researcher explained youth had gained tactics to stay engaged through deviate actions around parental or authoritarian figures, and method of creating a covert language through technology. Because of this new technology, innovations, and social online dwelling spaces, the youth find it imperative to stay engaged and active on the Internet. Days of youth sock-hops and Friday night mall loitering occasions were over. Digital natives are now leading a 24-hour-a-day social investment lifestyle on Facebook. Facebook itself is seen not as and event or an Internet location, but life itself.

\section{Addiction}

Many scholars have placed a label on today's youth being addictive in their behaviors from drugs to Internet usage. Carr [4] explained the addictive behaviors had an accumulative attention deficient disorder quality, while Prensky, $[8,9]$ contended the multitasking addiction was speculative and possibly productive in nature. Others such as Rodi, Spangler, Delorenzo, \& Kohun, [10] found the youth were unsophisticated and not able to function. Spangler [11] saw the youth's addictive behavior used in positive methods to engage others and become a technology-based ice breaking method.

Boyd's [2] paradigm shifted focus again to addiction issues being a mannerism for social engagement and a needed allotment in the culture like Spangler's views. Nevertheless, addiction can be seen as a positive attribute when the functions or outputs of the technology use are positive in nature. This was seen in Boyd's [3] research that determined the digital native culture embraced technology to become socially engaged and active in their own lives and others. This also was observed to learn social norms and cultural artifacts necessary for the youth to grow cognitively.

\section{RESEARCH METHODOLOGY}

This agile ethnographic was based on Spradley's [12] 12 steps of developmental research in a purposeful sampling at a Mid-Atlantic mid-sized university in Pennsylvania. Spradley's ethnographic observation system was utilized because of its direct nature to examine domains for social and cultural patterns. The researcher's system seeks to understand larger domain elements and patterns, and then through the spiraling down system understand smaller categories and how they relate to one another. The system engages a culture through submersed direct researcher observations of the participants in a deep and prolonged time frame to learn its meanings. The researcher generates a taxonomic analysis focusing on analyzing the situations for themes to create a "cultural inventor" of the domain. The participants, being and knowing they are actively being researcher, engage the researcher in an informant role. By utilizing the participants as active informants in the observations, a research is able to obtain deeper meanings and understandings of happenings and occurrences in the culture that other ethnographers fail to obtain in traditional covert analysis. It was for this reason alone the small and diverse population sample was selected. The purposeful sample fit the model Spradley's methodology requires for success and ease of unobtrusive observation with the ability to engage the participants as active informant roles once they are befriended. The purposeful ethnographic domain was chosen at the University whereby the researcher worked as a photojournalist. This atmosphere offered a diverse population and international student population. Along with its diverse and ease of access, the researcher was able to achieve having prolonged engagement and observed period of the population on a daily basis. An IRB was established through Robert Morris University and California University of Pennsylvania.

The ethnography was conducted inside five higher education classrooms and inside two social domains to engage in 
deep covert observations and gain rich meaningful insights into the culture. Informants in the domains were engaged to create a deeper understanding of observed behaviors. A population of 62 digital natives from a cross-section of the five colleges aided the researcher in creating a system of in-member checking validation system to the researcher's observations. Throughout the investigation, some 300 digital natives were observed in the culture's matrixes.

Table 1. Demographics

\begin{tabular}{|l|l|c|}
\hline Gender & Informant Focus Groups & Responses \\
\hline Female & Undergraduate student & 27 \\
\hline Male & Undergraduate student & 35 \\
\hline Total & Informants & 62 \\
\hline $\begin{array}{l}\text { Male } \\
\text { Female }\end{array}$ & $\begin{array}{l}\text { Undergraduate } \\
\text { Ethnography }\end{array}$ & $300+$ \\
\hline
\end{tabular}

The researcher first observed the Informants in a covert ethnographic manner prior to engaging them in meaningful conversations about witnessed behaviors. After completion of the ethnography engagement, youth were organized into structured informant groups that were each asked to label their own culture. The youth were then asked a series of questions based on the literature review that aided the researcher in clarifying observed artifacts and meanings. The final set of informant focus questions asked the digital native higher education youth to disclose the point of self-awareness of their addiction to technology.

\section{VALADATION}

To ensure validation of the ethnographic data collection, the volunteer informant groups were utilized to confirm the observations. The informant groups also offered deeper knowledge into the culture's meanings, artifacts, and point of addiction knowledge.

To ensure confidence in the ethnography observations, an inter-code validation system was conducted. A peer researcher was asked to access the same domains following the researcher's codebook that was designed from key literature findings and key themes found in the current digital native literature. The inter-coder validation reached a $90 \%$ confidence in reliability.

\section{POINT OF ADDICTION}

Sixty-two digital natives in five separate informant groups unified a point of addiction: the point of purchase of their first iPhone or Smartphone. More importantly, the youth unified in knowledge that their addictive behaviors were deeply rooted when their Smartphones were first broken, lost, or had dwindling battery power.

Ethnographically digital natives were observed in constant connectivity and usage with their Smartphones. The youth, who were unable to utilize the innovations beyond simplistic Google searches, texting, and app application use, were often observed disheveled with innovative considerations like accessing QR Codes. In a teaching with innovations education major classroom, the ethnographer observed the youth in a state of confusion and frustration. Interestingly, the 2015 digital native youth became distraught once their batteries suffered diminished supply from what they considered trivial use.

Informants disclosed to reduce frustration and anxiety; they often seek out positions that offer access to utility connections such as a wall plug. One informant offered a disclosure about how he has befriended other digital natives that have power sources. The informant said he would form friendships or a bond with another classmate that he has no common interests in knowing or being friendly with if the person has brought to class an iPhone charger. This was also a common disclosure in the informant focus groups whereby digital natives disclosed they too consider the same options when their Smartphones liquidated stored power from use. 


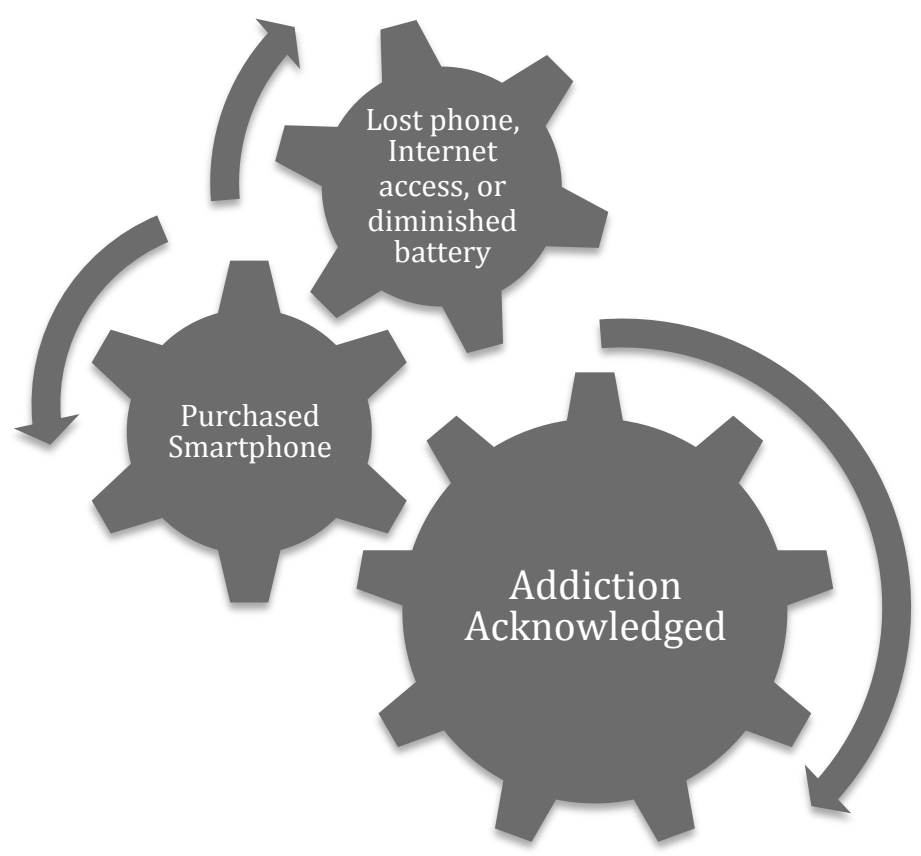

Figure 1. Technology Addiction Life Cycle

Other informants disclosed methods to eliminate anxiety from their lives from loss of power, connectivity, or phone use by simply surrounding themselves in connectivity positive areas only. Informants stated they would choose situations and travel arrangements to stay in constant connectivity and the ability to maintain Smartphone charge. Other informants disclosed information that confirmed their addiction through detailed situations of anxiety suffering from connectivity loss.

\section{CONNECTIVITY LOSS}

A male informant disclosed during a recent skiing adventure that he lost his phone on slopes. After reaching the bottom of the slope, and discovering his pocket was empty that housed his iPhone, he suffered immediate anxiety. The youth explained, in a state of panic from disconnection, he attempted to climb back up the mountainside in search of the lost Smartphone. The meritless adventure ended in the youth stomping through lengths of snow filled trails backtracking his downhill slalom.

Another digital native male informant disclosed how he would stay inside of his parked automobile for hours to stay connected if his family's farmhouse looses power in its rural location. The informant stated he stay in constant connectivity once for multiple days during a power outage and even sleeping in his automobile to maintain a Smartphone charge. Others stated they committed ignorant acts of blocking other natives from outlets in hallways or classrooms to maintain a Smartphone charge. One female informant, along with many other informants in the focus groups, stated she would "leave" class and go home if her Smartphone become low in charge, and she has forgotten her charger. Interestingly, to combat this situation, the university has invested in "charge stations" across the campus to aid students in battery maintaining and anxiety issues due to loss of connectivity through Smartphones.

United the youth were observed suffering anxiety issues in classes and in social domains when Smartphone power sources diminished. Informants in the focus groups unified disclosing anxiety issues from separation and loss of Smartphone access. The deep-seated addiction was confirmed through the in-member checking by informants. Informants disclosed that anxiety was greatly increased in their lives if they knew there would be connectivity loss from a dead battery, or inability to connect.

Ethnographically digital natives were observed leaving classrooms when Internet connectivity was displaced. The 
youth, in a computer science course, were witnessed becoming frantic when a professor locked them out of Internet access. The youth were witnessed become frantic and unable to maintain focus. Physical anxiety issues were witnessed to the point of students become so frustrated that they left the classrooms and entered hallways to seek a "fix" to their addiction loss through personal Smartphones. In a second situation, an education classroom in Keystone Hall, a power outage plunged the youth into anxiety from instant disconnection. The youth became instantaneously distraught from loss of Internet provisions. This included their desktop personal computers, and WIFI based innovations. The youth, after a series of swirling around episodes seeking an answer to the disconnection from other anxiety filled peers, sought through their personal belongings to find a Smartphone cell based Internet connection. Interestingly one should note, the youth informants in the classroom, unanimously disclosed that they were all posting on Facebook about the Internet outage and informing other peers to "Not come to class" because of the disconnection.

\section{RESULTS, CONCLUSION, AND FORWARDING THOUGHTS}

This paper first recognized the digital natives literatures' knowledge of addiction and the gap in the literature about addiction knowledge. Second this paper sought the need for clarification and a directed formation of when digital natives first placed merit or knowledge to their own addiction discoveries.

Through informant interviews and the ethnographic observations this research sought to fill the gap in the digital native literature. The paper has helped describe digital native addiction knowledge and the point of an individual's understanding or knowledge of addiction to connectivity. Although this research did find a universal point of addiction in the digital native higher education students, the research contends there should be additional research generated in the paradigm to cross validate this data. Future research should be conducted in middle and high schools were today's 2015 youth are also invested and bestowed with Smartphone technologies. Furthering this research could create a more artifacts in the culture and meanings created form the innovations and technology usage.

This research discloses a single point of addiction through the Smartphone innovation: purchase and loss. The instant connectivity through the use of the Smartphone innovations sees to be the main reason for the increase in the culture's addictive behaviors. The ability of the Smartphones to increase connectivity because of the innovation's cellular or WIFI connectivity and low purchase price investments has also in this researcher's views helped to additionally diminished the technology gap.

\section{Limitations to the Study}

Because the scope of this research did not extend into describing and identifying technology gap diminishing natures, the researcher proposes the need for a literature review and study on the current state of the technology gap. This information would extend this study, and possible create a new paradigm or disclose a shift in the current paradigm on Internet based technologies and Smartphone innovations. Additionally the research should be extended into different generational gaps. Including preteen youth and high school aged teenagers into the study could disclose deeper insights into reasons or points of addition in the culture. A larger overall scope, which consists of different regions around America, would also aide the researcher in establishing cross-country generalization to the findings. Additionally, furthering researchers in Europe and other countries should recreate this study to create and determine if there is a global generalizable fact about the point of addiction in the digital native paradigm.

\section{REFERENCES}

1. Bauerlein, M. (2009). The dumbest generation: How the digital age stupefies young americans and jeopardizes our future (or, don't trust anyone under 30). New York, NY: Tarcher.

2. Boyd, D. (2014). It's complicated: The social lives of networked teens (1 edition.). New Haven: Yale University Press.

3. Ibid.

4. Carr, N. (2008). The big switch: Rewiring the world, from Edison to Google. W. W. Norton \& Company. 
5. Carr, N. (2011). The Shallows: What the Internet is doing to our brains (Reprint.). W. W. Norton \& Company.

6. Howe, N., \& Strauss, W. (1993). 13th gen: Abort, retry, ignore, and fail? New York: Vintage Books.

7. Prensky, M. (2001a). Digital natives, digital immigrants. On the horizon (MCB University Press), 9(5), 1-6.

8. Prensky, M. (2001b). Digital natives, digital immigrants, Part II: Do they really think differently? On the Horizon (MCB University Press), 9(6), 9.

9. Prensky, M. (2012). From digital natives to digital wisdom: Hopeful essays for 21 st century learning. Thousand Oaks, Calif.: Corwin.

10. Rodi, A., Spangler, S., Delorenzo, G., \& Kohun, F. (2014). A case study: Are digital natives dead? What are the key factors and perceptions librarian's view of the digital native culture in higher education? Issues in Information Systems 15(2), 207-213.

11. Spangler, S. (2015). Ethnography: The deconstruction of individualism caused by technology innovations in a microenvironment: Herron Hall Fitness Center. Journal of Ethnographic \& Qualitative Research and Conference paper Las Vegas, Nevada.

12. Spradley, J. P. (1980). Participant observation (1st ed.). Holt, Rinehart and Winston.

13. Tapscott, D. (1999). Growing up digital: The rise of the Net Generation (New edition edition.). New York: McGraw-Hill.

14. Turkle, S. (2011). Alone together: Why we expect more from technology and less from each other (1st ed.). Basic Book. 